Original Article

\title{
Emergency Services Received By the Patients with the Standard Protocol of Emergency Room
}

\author{
Sonia Karen Liz Sequera ${ }^{1}$, Savitha Pramilda Cutinho ${ }^{1}$, Adriel Benita Quadros ${ }^{1}$, Stephy Binny ${ }^{1}$, \\ Wandashisha Siangshai ${ }^{1}$ \\ ${ }^{1}$ MSc (N), PGDC, Father Muller College of Nursing, Father Muller Road, Kankanady, Mangaluru- 575002, ${ }^{1} \mathrm{PhD}(\mathrm{N}), \mathrm{MSc}(\mathrm{N})$, \\ Coombe Women and Infant University Hospital.
}

Corresponding Author: Sonia Karen Liz Sequera, MSc (N), PGDC, Father Muller College of Nursing, Father Muller Road, Kankanady, Mangaluru, Mobile :+91 73530 74151, E-Mail : soniakaren@fathermuller.in

Received : $\quad: 13.10 .2018$

Review Completed : 21.11.2018

Accepted

: 26.11.2018

Keywords : Emergency Services, Patient, Emergency room

\begin{tabular}{|c|}
\hline Access this article online \\
\hline Quick Response Code \\
\hline
\end{tabular}

Abstract :

Emergency Services are life saving measures for critically ill patients. If critically ill patients are not treated on time, the morbidity rates are likely to increase day by day. Hence, appropriate emergency care should be provided in each Emergency Department of the hospitals. This study intends to assess the Emergency Services provided to the patients in the Emergency Room of a hospital and also assess the level of patient satisfaction regarding the Services received.

Aims: To identify the services received by the patients in the emergency room and to find out the patient satisfaction regarding the services received and to associate satisfaction level of emergency services with selected demographic variables.

Settings and Design: Emergency department of a selected medical college hospital, Mangaluru and a Cross sectional descriptive study design.

Material and Methods: A protocol based checklist of Emergency Services and a Semantic Differentiation scale to assess the satisfaction level of emergency services.

Statistical analysis used: Frequency, Percentage, Mean, Standard Deviation and Chi-Square for association.

Results: The major findings of the study shows that out of 60 patients $55 \%$ rated the services available as very good, $43 \%$ as good \& $2 \%$ as satisfactory and with regard to satisfaction level, $90 \%$ patients were satisfied regarding the Emergency Services received in an Emergency Room.

Conclusions: Pooled results showed that majority of the patients were satisfied with the emergency Services received and rated the available services as very good. Hence it reveals that the health care professionals of the selected hospital followed the emergency protocol of the hospital.

\section{Introduction}

The emergency department of the hospital is responsible for the medical and surgical care to the patients arriving in need of immediate care. Emergency department personnel respond to certain situations within the hospital as per the priority. Due to unplanned nature of patient attendance, the department must provide initial treatment for a broad spectrum of illness and injuries, some of which may be life-threatening and require immediate attention. Every emergency department has a triage or triaging area to sort incoming patients. A gap between guidelines or protocols and clinical practice often exists, which may result in patients not receiving appropriate care ${ }^{1}$. Clinical practice guidelines and protocols are developed to improve quality of care, to reduce variation of practice and to ensure that evidence is used appropriatly ${ }^{2}$. It is suggested that effective implementation should ensure guideline adherence in practice and subsequent lead to improved patient outcomes. When professionals do not adhere to guidelines and protocols, patient in the emergency care setting may not receive appropriate and adequate care and quality of care can be threatened. ${ }^{1}$ Patient satisfaction deserves attention not only because it is an intrinsically worthy goal, but also because it is 
potentially a significant mediator for a range of important outcomes. Satisfied patients may be more compliant with their medical regimens, suggesting that satisfaction may be an important component in promoting health and wellbeing. ${ }^{2}$ Hence the study aimed to identify whether the services received by the patients in the emergency room is according to the standard protocol, and also asses patient satisfaction regarding the received emergency services.

\section{Materials \& Methods}

A cross sectional descriptive study design was employed to identify the services received by the patients in the Emergency Room, and also to assess the patient satisfaction regarding the emergency services. Convenient sampling technique was used. The selection criteria included patient with the age group 18 years and below 75 years who have availed the emergency services in the emergency room. Patients who were unconscious and not able to respond to the questionnaire were excluded from the study. The study was performed in the emergency department of a selected hospital Mangaluru.

The self developed tool for data collection consisted of baseline proforma, a checklist of emergency services rendered by the emergency department as per the protocol and a semantic differentiation scale with two extremes being satisfied and unsatisfied, where patients gave opinion regarding the satisfaction of emergency services received. The checklist of emergency services had 23 items with three options being 'yes', 'no' and 'not applicable'. The tool was validated by the experts from various fields and after pretesting reliability of the tool was done using split half method. The reliability co-efficient obtained was $r=1$. The ethical clearance was obtained for the study and permission was obtained from the selected hospital to conduct the study. Informed consent was obtained and confidentiality of information was assured. Pilot study was done and no issues related to the study were identified. The main study was done on 60 patients who attended the emergency department for the emergency services. The average time taken to complete the checklist and semantic differentiation scale was about
15-20 minutes. The data collection was terminated by thanking the subjects for their participation and cooperation. The data collected was compiled for analysis.

\section{Results}

The data was analysed using SPSS version 20.

More than half patients (55\%) rated the emergency services as very good and very few (2\%) rated the services as poor.

Table 1 shows the assessment of services received by the patients in the Emergency Room

$\mathrm{n}=60$

\begin{tabular}{|l|c|c|}
\hline Services received & Frequency (f) & Percentage (\%) \\
\hline Poor & 0 & 0 \\
\hline Satisfactory & 1 & 2 \\
\hline Good & 26 & 43 \\
\hline Very good & 33 & 55 \\
\hline
\end{tabular}

Table 2 shows the mean, standard deviation and mean percentage of received emergency services as per the protocol in the emergency room

\begin{tabular}{|l|c|c|c|c|c|}
\hline Variable & Items & $\begin{array}{c}\text { Maximum } \\
\text { Score }\end{array}$ & Mean \pm SD & Mean \% & $\begin{array}{c}\text { Rating of } \\
\text { emergency } \\
\text { services }\end{array}$ \\
\hline $\begin{array}{l}\text { protocol based } \\
\text { Emergency } \\
\text { Services }\end{array}$ & 23 & 46 & $40.63 \pm 3.32$ & 88.26 & Very good \\
\hline
\end{tabular}

The patient's level of satisfaction was assessed using a semantic differentiation scale and the data is presented in figure 1.

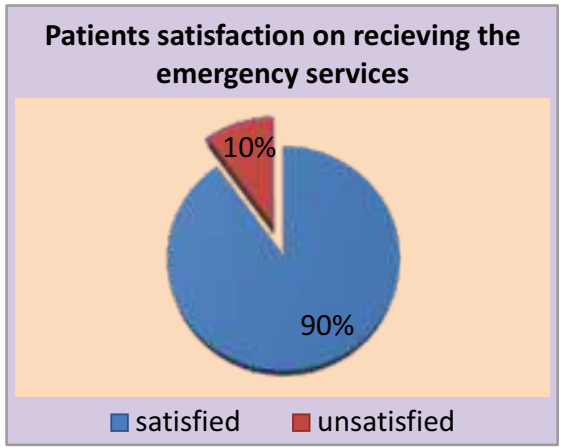

Figure 1 : Pie chart showing the patient's satisfaction regarding the Emergency Services of the Emergency Room

The findings of the study showed that $90 \%$ of the patients were satisfied with the emergency services whereas, $10 \%$ were unsatisfied. There was no significant association of emergency services received with the demographic variable. 


\section{Sample Characteristics}

Out of 60 patients surveyed, majority (37\%) of the patients were above the age of 50 years and had education up to $10^{\text {th }}$ standard (47\%). More than half (55\%) work in private sector and belong to nuclear family (53\%).With regard to the purpose of visit to emergency department, study shows that $17(28.33 \%)$ patient's came to the Emergency Room with cardiac problems, 13(21.6) with road traffic accident and body pain, 6(10\%) were having fever and respiratory problems, $3(5 \%)$ had fracture and $2(3.33 \%)$ with giddiness.

Table : Below shows the frequency and percentage of emergency services received as per the protocol in the emergency room

\begin{tabular}{|c|c|c|c|c|}
\hline SI No. & Statement & $\begin{array}{l}\text { Yes } \\
f(\%)\end{array}$ & $\begin{array}{c}\text { No } \\
f(\%)\end{array}$ & $\begin{array}{l}\text { Not Applicable } \\
\text { f (\%) }\end{array}$ \\
\hline 1 & Patient coming to the emergency room was allowed to be at least one attender. & $58(97)$ & $2(3)$ & - \\
\hline 2 & There was delay in attending the patient. & $49(82)$ & $11(18)$ & - \\
\hline 3 & Wheelchair or stretcher was made available, to the patient at the entrance. & $51(85)$ & $8(13)$ & $1(2)$ \\
\hline 4 & Patient was received by an on-duty staff at the entrance. & $56(93)$ & $4(7)$ & - \\
\hline 5 & You were directed to register before treatment. & $49(82)$ & $11(18)$ & - \\
\hline 6 & Basic data such as name, age, gender etc were collected for registration. & $56(93)$ & $3(5)$ & $1(2)$ \\
\hline 7 & Patient was immediately attended and assessed by a staff nurse. & $58(97)$ & $2(3)$ & - \\
\hline 8 & Patent was initially assessed by the doctor on duty. & $57(95)$ & $3(5)$ & - \\
\hline 9 & $\begin{array}{l}\text { Vital signs such as blood pressure, pulse, temperature, etc were checked by the } \\
\text { nurse within } 10 \text { minutes of arrival. }\end{array}$ & $57(95)$ & $3(5)$ & - \\
\hline 10 & Detailed history with allergic history was collected by nurse/doctor. & $55(92)$ & $5(8)$ & - \\
\hline 11 & $\begin{array}{l}\text { An identification band was put on the patient during the transfer from the } \\
\text { Emergency Room. }\end{array}$ & $52(87)$ & $8(13)$ & - \\
\hline 12 & After the assessment the nurse/doctor communicated regarding the patient's & & & \\
\hline & condition throughout the stay in the Emergency Room. & $56(90)$ & $5(8)$ & $1(2)$ \\
\hline 13 & Consent for treatment was obtained. & $60(100)$ & - & - \\
\hline 14 & Investigations were carried out immediately (eg :CT scan, X-ray, Blood test etc ) & $57(95)$ & $2(3)$ & $1(2)$ \\
\hline 15 & Specialist consultation was sought by the duty doctor. & $56(93)$ & $3(5)$ & $1(2)$ \\
\hline 16 & Patient was reassessed by the specialist if required. & $52(87)$ & $6(10)$ & $2(3)$ \\
\hline 17 & Patient was reassessed by the duty doctor / nurse every 30 minutes. & $53(88)$ & $7(12)$ & - \\
\hline 18 & Patient was shifted out within 2 hours of arrival from the Emergency Room. & $45(75)$ & $13(22)$ & $2(3)$ \\
\hline 19 & Discharge/ Transfer out process was discussed with the patient/family members. & $51(85)$ & $8(13)$ & $1(2)$ \\
\hline 20 & $\begin{array}{l}\text { Treatment summary was given and explained to patient/ family } \\
\text { members during discharge. }\end{array}$ & $5(91)$ & $4(7)$ & $1(2)$ \\
\hline 21 & Patient was monitored throughout their stay in the Emergency Room. & $54(90)$ & $5(8)$ & $1(2)$ \\
\hline 22 & In case of accident, police intimation was given & $12(20)$ & $9(15)$ & $39(65)$ \\
\hline 23 & Patient was made to wait for more than 4 hours. & $8(13)$ & $52(87)$ & - \\
\hline
\end{tabular}

\section{Discussion}

Patient satisfaction is among the most important factors and indicators of quality in any hospital. Surveys act as a means to measure the efficacy of a department worldwide. In the present study the overall mean rating of emergency services provided by the personnel of the emergency department as per the protocol is very good. The study results also showed that majority of the patients were above 50 years of age and have education up to $10^{\text {th }}$ standard. Most of them belong to nuclear family and it was revealed that patients attended emergency services due to various health problems such as cardiac issues, respiratory problems, fever, giddiness, body pain, fracture and road traffic accidents. A similar study conducted in 2014 at Karachi revealed that majority of patients belonged to age group 60 and above i.e. $30.9 \%(n=107)$ and more than half $57.8(n=200)$ were females ${ }^{3}$.

In the present study, more than half of patients (55\%) rated the emergency services as very good and very few (2\%) rated the services as poor and out of 60 patients, $90 \%$ of the patients were satisfied with the emergency services whereas, $10 \%$ were unsatisfied. There was no significant association of emergency services received with the demographic variable. In the similar study, Overall patient 
satisfaction was 4.27 out of 5 with $84.6 \%$ showing satisfaction with emergency department services while when overall satisfaction level was looked closely in terms of different triage categories the results turned out to be $79 \%, 83 \%$ and $88 \%$ in P1, P2 and P3 categories respectively ${ }^{3}$. This could be because of the fact that these are high acuity patients which either have life threatening emergencies or are critically ill and are seen first if not immediately.

Nursing care and attitude can have significant impact on patient satisfaction. This present study also showed that patients are well satisfied regarding the emergency services and the services were provided as per the protocol followed by the hospital. The present study throws light on the satisfaction of patients regarding the emergency services provided at a selected emergency department of a hospital. The satisfaction variable in this study provides a feedback regarding the hospital emergency services that will enable the health care authorities to ensure a good quality services. It will help the hospital authorities to maintain the quality services so as to meet the standards of an accreditated health care infrastructure. The present study provides a positive feedback with adequate level of satisfaction regarding emergency services.

\section{References}

1. Ebben RH, Vloet LC, Verhofstad MH, Meijer S, Mintjes-de Groot JA, van Achterberg T. Adherence to guidelines and protocols in the pre hospital and emergency care setting: a systematic review. Scand J Trauma Resusc Emerg Med. 2013 Feb 19;21:9. doi: 10.1186/17577241-21-9.

2. Boudreaux ED, O'Hea EL. Patient satisfaction in the emergency department. A review of the literature and implications for practice. $J$ Emerg Med. 2004 Jan; 26(1):13-26.

3. Khursheed M, Fayyaz J, Zia N, Feroze A, Jamil A et al. Real-Time Patient Satisfaction of Emergency Department Services in a Tertiary-Care Hospital in Karachi, Pakistan . Emergency Med. 2014; 4(3):188. doi:10.4172/2165-7548.1000188.
Further studies with a better methodology are required to draw definite conclusions. This study could be replicated on a larger sample and different emergency departments of various hospitals for generalizing the findings. Replication of the same study can be done on the other population segments like patient bystanders who accompany the patients to the emergency department and are available throughout the emergency care.

\section{Conclusions}

Patient satisfaction is a powerful quality improvement tool to measure the quality of care patient received. It deserves attention not only because it is an intrinsically worthy goal, but also because it is a potentially significant mediator for a range of important outcomes. The protocol in a hospital acts as a checklist to follow up the services provided and will also be a backbone to provide quality care to the patients attending the heath care facility.

\section{Acknowledgement}

The authors would like to acknowledge the support of Father Muller Charitable Institutions, Mangaluru, The Principal, Father Muller college of Nursing, teaching faculty, experts for their guidance and Participants of the study for their whole-hearted participation. 